\title{
New treatment options in the management of hypertension: appraising the potential role of azilsartan medoxomil
}

This article was published in the following Dove Press journal:

Integrated Blood Pressure Control

9 March 2012

Number of times this article has been viewed

\author{
Massimo Volpe ${ }^{1,2}$ \\ Carmine Savoia' \\ 'Division of Cardiology, Department \\ of Clinical and Molecular Medicine, \\ Sant'Andrea Hospital, Sapienza \\ University of Rome, Rome Italy; \\ ${ }^{2}$ IRCCS Neuromed, Pozzilli (Is), Italy
}

\begin{abstract}
Renin-angiotensin-system (RAS) activation plays a key role in the development of hypertension and cardiovascular disease. Drugs that antagonize the RAS (angiotensin-converting enzyme [ACE] inhibitors and angiotensin receptor blockers [ARBs]) have proven clinical efficacy in reducing blood pressure values and cardiovascular morbidity and mortality. ACE inhibitors partially inhibit plasma ACE, and angiotensin II generation. Thus, ARBs, which block selectively type 1 angiotensin II receptor ( $\mathrm{AT}_{1} \mathrm{R}$ ), have been developed and used in the clinical management of hypertension and cardiovascular disease. Experimental and clinical trials with ARBs indicate that this class of drug represents an effective, safe and well tolerated therapeutic option for the prevention and care of hypertension, even though there is no proven superiority as compared to ACE inhibitors except for the better tolerability. Most ARBs may not completely inhibit the $\mathrm{AT}_{1} \mathrm{R}$ at the approved clinical doses. Azilsartan medoxomil is a newly approved ARB for the management of hypertension. This ARB induces a potent and long-lasting antihypertensive effect and may have cardioprotective properties. This article reviews the current evidence on the clinical effectiveness of azilsartan in hypertension.
\end{abstract}

Keywords: RAS, sartan, hypertension, cardiovascular protection

\section{Introduction}

Hypertension is a chronic disease associated with significant cardiovascular morbidity and mortality. Improved control of blood pressure in patients with hypertension is a key requirement to reduce cardiovascular and renal morbidity and mortality. ${ }^{1,2}$ Despite the effectiveness of the currently available antihypertensive agents, hypertension remains inadequately controlled, with slightly less than half of patients who receive treatment successfully achieving the goals for systolic and diastolic blood pressure. ${ }^{3,4}$

The renin-angiotensin-system (RAS) plays a central role in the pathophysiology of hypertension, cardiovascular and renal disease. ${ }^{5,6}$ It contributes to the increase of blood volume and arterial pressure, to the alterations of endothelial function, vascular reactivity, fibrosis, tissue remodeling, oxidative stress and inflammation which may predispose to the development of cardiovascular disease..$^{5-7}$ While there are many drug classes available to reduce blood pressure, pharmacological agents that modulate the RAS are more commonly chosen as the first drug or in combination therapy because of their efficacy and the lowest side effect profile among the antihypertensive agents. The development of angiotensin-converting enzyme (ACE) inhibitors has represented a cornerstone for the treatment of various pathological cardiovascular conditions, including hypertension. However ACE inhibitors only partially inhibit the formation of angiotensin II (Ang II). From this point of view, angiotensin-receptor blockers (ARBs) provide a more rational
Correspondence: Massimo Volpe Cardiology Unit, Sant'Andrea Hospital, Clinical and Molecular Medicine Department, Sapienza University of Rome, Via di

Grottarossa 1037/1039,

00189 Rome, Italy

Tel $+39063377556 \mathrm{I}$

Fax +390633775061

Email massimo.volpe@uniromal.it 
tool to inhibit RAS activity since they block selectivity the coupling of Ang II to type 1 angiotensin II receptor (AT $R$ ). For this reason they have been developed and increasingly used in the clinical management of hypertension and cardiovascular diseases. Among the compounds that antagonize the RAS, ARBs (which include several molecules such as losartan, candesartan cilexetil, valsartan, irbesartan, telmisartan, eprosartan and olmesartan medoxomil, and the newest azilsartan medoxomil) represent today the best-tolerated class among antihypertensive agents. ${ }^{8}$ The clinical efficacy of ARBs has been established in hypertensive patients, particularly in terms of reduction in cardiovascular morbidity and mortality, prevention and regression of end organ damage and the slow progression of nephropathy.

\section{Blocking the RAS: ARBs and cardiovascular protection}

RAS blockers provide independent actions on end-organ protection, beyond their blood pressure lowering effect. ${ }^{9}$ This has been shown with both ACE inhibitors and ARBs. A large body of evidence indicate that ACE inhibitors are effective for the treatment of various pathological conditions including arterial hypertension, diabetes, and cardiovascular or cerebrovascular diseases. ${ }^{10-13}$ However ACE inhibitors antagonize the RAS only in part. Indeed, these drugs partially inhibit plasma ACE and Ang II generation, even at high dosages. ${ }^{14}$ Nevertheless, Ang II can be produced by alternative pathways (chymases, caspases, elastases) in the cardiovascular system. ${ }^{15,16}$ Therefore, the selective blockers of the $\mathrm{AT}_{1} \mathrm{R}$, have been developed and progressively used in the clinical management of hypertension and cardiovascular diseases. The class of ARBs includes several compounds that share similar effects. However, the different molecules may present specific pharmacokinetic and pharmocodynamic properties. Moreover, some of the molecules may have ancillary effects such as the increased urinary uric acid excretion (losartan in particular) and may activate peroxisome proliferator-activated receptor (PPAR)- $\gamma$ which may contribute to a favorable metabolic profile. This latter effect has been described for the ARBs telmisartan, irbesartan, candesartan, and losartan. ${ }^{17}$

Randomized clinical trials have proven benefits for the therapy with ARBs in primary and secondary prevention in several pathological conditions including hypertension, coronary artery disease, congestive heart failure, and renal disease. ARBs have shown cardioprotective effects in patients with hypertension and additional risk factors. In the Losartan Intervention For Endpoint Reduction (LIFE) ${ }^{18}$ the
ARB losartan was compared to atenolol in over 9000 patients with moderate-to-severe hypertension and left-ventricular hypertrophy. Losartan improved the primary composite endpoint, which included cardiovascular mortality, stroke, and myocardial infarction, independently by blood pressure reduction. The losartan treatment was also associated with a $25 \%$ lower incidence of new-onset diabetes. This was observed also in the placebo-controlled Kyoto Heart Study ${ }^{19}$ in which valsartan used as add-on therapy reduced the incidence of new onset of diabetes as well as cardiovascular outcomes in about 3000 hypertensive patients with additional risk factors. A recent meta-analysis has also proven the effectiveness of RAS blockers in reducing the occurrence of new-onset diabetes. Hence the ACE inhibitors or ARBs should be preferred in patients with clinical conditions that may increase the risk of developing diabetes. ${ }^{20}$

Both hypertension and diabetes may induce renal damage in patients at risk for cardiovascular diseases. In turn, renal disease may increase the cardiovascular risk even at a preclinical stage (ie, presence of microalbuminuria). Furthermore, diabetic nephropathy is responsible for the majority of end-stage renal disease in most countries. Antihypertensive treatment may prevent the progression of the disease. In particular, agents that block the RAS can delay or prevent the diabetic nephropathy even at the initial stages as well as reduce the degree of albuminuria and the progression to advanced renal disease. In the Randomised Olmesartan And Diabetes Microalbuminuria Prevention (ROADMAP) study, the ARB olmesartan was associated with a delayed onset of microalbuminuria, although the drug did not reduce the cardiovascular complications associated with the diabetic state and the number of cardiovascular events. ${ }^{21}$ The ARB irbesartan has been shown to delay the progression from microalbuminuria to overt proteinuria and to restore normoalbuminuria in a significant proportion of patients with hypertension and type 2 diabetes. ${ }^{22}$ Moreover, irbesartan protected against advanced nephropathy in hypertensive patients with type 2 diabetes, independently by blood pressure control. ${ }^{23}$

Ventricular dysfunction and heart failure may develop in the progression of the cardiovascular disease in high cardiovascular risk patients, which are generally older than the patients at the early stages of the cardiovascular continuum and have often several comorbidities. ${ }^{24} \mathrm{ARBs}$ were equal to ACE inhibitors in reducing all-cause mortality in patients with left-ventricular dysfunction or heart failure postmyocardial infarction ${ }^{24-26}$ as well as in chronic heart failure patients. ${ }^{27,28}$

In patients at higher cardiovascular risk, ARBs have been shown to induce similar cardiovascular protective effects. 
Telmisartan was proven to have cardioprotective effects in high cardiovascular risk patients who were intolerant to ACE inhibitors. ${ }^{29}$ In over 25,000 patients with coronary, peripheral or cerebrovascular disease and diabetes with end organ damage the Ongoing Telmisartan Alone and in Combination with Ramipril Global Endpoint Trial (ONTARGET) ${ }^{30}$ has shown that telmisartan had similar effect to ramipril on the primary composite end point (including cardiovascular death, myocardial infarction, stroke or hospitalization for heart failure) and death from any cause. This was the first trial to compare an ARB with the ACE inhibitor ramipril, which has been proven to improve cardiovascular outcomes in the HOPE trial. ${ }^{31}$ In hypertensive patients with a history of a cerebral event within the previous 24 months eprosartan showed to be superior to the calcium-channel blocker nitrendipine for the secondary prevention of morbidity and mortality after stroke. ${ }^{32}$ However, valsartan was comparable to amlodipine on the primary composite end-point in the Valsartan Antihypertensive Long-term Use Evaluation (VALUE) trial which included over 15,000 patients with hypertension and additional risk factors (coronary heart disease, diabetes, high cholesterol). ${ }^{33}$

Thus the clinical experience with ARBs consistently indicates that this class of drugs represents an effective, safe and well tolerated therapeutic alternative for the prevention and care of cardiovascular disease, even though there is no proven superiority as compared to ACE inhibitors except for the well documented better tolerability. Caution should be used in considering ARBs interchangeably, although a class effect can be advocated for the clinical effectiveness of ARBs. Therefore, in the clinical practice it is preferable to choose the ARB that is proven effective, based on specific evidence derived from clinical studies.

\section{Azilsartan: evidence of effectiveness}

While ARBs are effective in clinical practice and well tolerated, the extent to which they can reduce blood pressure is eventually considered insufficient and a combination therapy is required in a significant percentage of hypertensive patients. ${ }^{34}$ Moreover most ARBs may not completely inhibit the $\mathrm{AT}_{1} \mathrm{R}$ at the approved clinical doses.

Azilsartan medoxomil is a newly approved ARB for the management of hypertension. It is a prodrug that is quickly hydrolyzed to the active moiety azilsartan, a potent and highly selective ARB with estimated bioavailability of $60 \%$ and elimination half-life of 12 hours. ${ }^{35}$ Findings from pharmacokinetic and dose-ranging studies have assessed that the effective therapeutic antihypertensive dosages of azilsartan medoxomil in humans vary from 40 to $80 \mathrm{mg}$ once daily. ${ }^{35}$ Experimental and clinical studies have shown that this new ARB induces a potent and long-lasting antihypertensive effect. In conscious spontaneously hypertensive rats (SHRs) and renal hypertensive dogs, azilsartan medoxomil induced more potent and longerlasting antihypertensive effects than olmesartan medoxomil, which is the newest to the market and has been reported to be most effective among ARBs in terms of blood pressure reduction. The persistent durability of the antihypertensive effects of azilsartan medoxomil may reduce the variations in blood pressure during the day. This may contribute potential protective effects on cardiovascular consequences. ${ }^{36}$

Clinical trials have compared azilsartan medoxomil with other ARBs in the class, by studying patients with primary hypertension in randomized, double-blind, multicenter studies using ambulatory (ABPM) and clinic blood pressure measurements (Table 1). Intraclass differences in blood pressurelowering effects within the ARB class cannot be recognized using clinic blood pressure measurements and may be better assessed with ABPM. ${ }^{37}$ Moreover, mean 24-hour systolic blood pressure has been shown to correlate with cardiovascular morbidity in patients with hypertension. ${ }^{38}$ Phase III studies evaluated and compared the efficacy of 24-hour mean systolic blood pressure and the safety of azilsartan ( $80 \mathrm{mg}$ once daily) with placebo and the maximal, approved doses of olmesartan

Table I Recent studies with the novel ARB compound azilsartan medoxomil in hypertensive patients

\begin{tabular}{|c|c|c|c|c|c|c|c|}
\hline Author & $\begin{array}{l}\text { Year of } \\
\text { publication }\end{array}$ & Population & $\begin{array}{l}\text { Population } \\
\text { size }\end{array}$ & Comparator & $\begin{array}{l}\text { Baseline } \\
\text { clinic BP } \\
(\mathrm{mmHg})\end{array}$ & $\begin{array}{l}\text { Basal 24-hour } \\
\text { mean BP } \\
(\mathrm{mmHg})\end{array}$ & $\begin{array}{l}\Delta \text { 24-hour BP after } \\
\text { treatment } \\
(\mathrm{mmHg})\end{array}$ \\
\hline White et $\mathrm{al}^{39}$ & 2011 & $\begin{array}{l}\text { Stage } 1-2 \\
\text { hypertension }\end{array}$ & $129 \mid$ & $\begin{array}{l}\text { Valsartan } \\
(320 \mathrm{mg}) \\
\text { Olmesartan } \\
(40 \mathrm{mg})\end{array}$ & $\begin{array}{l}156 \text { to } 158 / \\
92 \text { to } 93\end{array}$ & $\begin{array}{l}\mid 44 \text { to }|46| \\
88 \text { to } 90\end{array}$ & $\begin{array}{l}-5.4(95 \% \mathrm{Cl}:-8 . \mathrm{I}--2.8 \\
\text { SBP, vs valsartan })^{*} \\
-3.5(95 \% \mathrm{Cl}:-6.2--0.9 ; \\
\text { SBP, vs olmesartan })^{\S}\end{array}$ \\
\hline Sica et $\mathrm{al}^{40}$ & 2011 & $\begin{array}{l}\text { Stage I-2 } \\
\text { hypertension }\end{array}$ & 984 & $\begin{array}{l}\text { Valsartan } \\
\text { (320 mg) }\end{array}$ & |57.2/9|.2 & |45.6/87.9 & $\begin{array}{l}-2.69(95 \% \mathrm{Cl}:-3.49--\mathrm{I} .5 ; \\
\mathrm{DBP})^{*}\end{array}$ \\
\hline
\end{tabular}

Notes: The $\Delta 24$-hour $B P$ is referred to comparison with azilsartan medoxomil $80 \mathrm{mg}$; $* P<0.001 ; \$ P<0.008$.

Abbreviations: ARB, angiotensin-receptor blocker; BP, blood pressure; $\mathrm{Cl}$, confidence interval; SBP, systolic blood pressure; DBP, diastolic blood pressure. 
medoxomil (40 mg once daily) and valsartan (320 mg once daily) in hypertensive patients (stage 1-2 of hypertension) using ambulatory and automatically measured clinic blood pressure monitoring. ${ }^{39}$ Azilsartan medoxomil at a dose of $80 \mathrm{mg}$ once daily for 6 weeks showed superior efficacy to the top approved doses for hypertension of both valsartan and olmesartan. Moreover, also at the dosage of $40 \mathrm{mg}$ azilsartan medoxomil lowered clinic systolic BP to a greater extent than the other ARBs, suggesting that this novel agent has a greater potency than these other molecules at the dosages used in the study. Moreover, azilsartan was well tolerated and there was no increase in adverse events during this short-term trial. Across the effective dose range azilsartan showed superior efficacy compared to the ARB valsartan at its maximal recommended dose ${ }^{40}$ without any significant increase in adverse events. In particular, the antihypertensive effects, safety and tolerability of azilsartan medoxomil were compared to those of valsartan in patients with stage 1 or 2 hypertension in a 24 -week randomized, double-blind, parallel-group, multicenter trial. ${ }^{40}$ On the basis of either ABPM or automatically measured clinic blood pressure measurements azilsartan medoxomil at a dose of $40 \mathrm{mg}$ or $80 \mathrm{mg}$ once daily showed greater efficacy (about $10 \%$ in absolute rate) than a $320 \mathrm{mg}$ dose of valsartan, the highest approved dose for this drug. ${ }^{40}$

These findings suggest that azilsartan medoxomil can lower 24-hour blood pressure more effectively than maximally recommended doses of other ARBs. This suggests that there may be a measurable hierarchal response in the ARB class, as far as the blood pressure levels are considered. Azilsartan medoxomil is expected to be able to control the blood pressure for a 24-hour period, which may contribute to the prevention of cardiovascular events. Indeed, elevations in blood pressure around midnight and early morning are important predictors of central nervous system and cardiovascular outcomes in hypertensive patients. ${ }^{41,42}$

Azilsartan medoxomil is highly potent in inhibiting the specific binding of 125I-Sar1-Ile8-Ang II to human $\mathrm{AT}_{1} \mathrm{R}$, and it is a slowly dissociating Ang II receptor blocker. Indeed the inhibitory effect of azilsartan medoxomil persisted after washout of the free compound when compared to other ARBs (including olmesartan, telmisartan, valsartan, and irbesartan) which presented attenuated inhibitory effects with washout. In this regard, the inhibitory effects of azilsartan on Ang II-induced contractile response persisted after washout in vascular strips and Chinese hamster ovary $(\mathrm{CHO})$ cells which overexpress the human $\mathrm{AT}_{1} \mathrm{R}^{43}$ Thus Azilsartan medoxomil may prove to provide a more complete antagonism against endogenous Ang II. This may explain at least in part the greater blood pressure reduction associated with azilsartan. However, these in vitro determinations are yet to be supported in the whole animal or in human studies.

\section{Beyond blood pressure control: pleiotropic effects of azilsartan}

Hypertension is often associated with insulin resistance which predisposes to the development of metabolic syndrome and/or diabetes. Blockade of RAS/AT $\mathrm{R}_{1}$ signaling has been shown to improve the metabolic syndrome in clinical and experimental studies. ${ }^{44}$ Some ARBs including losartan, irbesartan, and telmisartan have been shown to improve insulin sensitivity in rodents and humans, ${ }^{45,46}$ suggesting the possible involvement of the excess of Ang II in the development of insulin resistance. Olmesartan medoxomil produced dose-related improvements in the insulin sensitivity of SHRs. ${ }^{36}$ Candesartan cilexetil improved the insulin sensitivity of essential hypertensive patients. ${ }^{47}$

Most recently, azilsartan medoxomil has been proven to improve insulin sensitivity in hypertensive rats. ${ }^{36}$ Interestingly, it has been shown that azilsartan medoxomil is more effective than candesartan in reducing plasma concentrations of glucose and fatty acids in normotensive mice. Furthermore this novel ARB decreases adipose tissue weight and adipocyte size and increases adipose expression of PPAR- $\gamma$ and its target gene adiponectin, independently of its effects on blood pressure and plasma insulin concentrations. ${ }^{48}$ It has also been shown that azilsartan medoxomil induces insulinsensitizing effects in obese Koletsky rats, independently of decreases in food intake and body weight increase or of the activation of adipose PPAR- $\gamma$, the master regulator of adipogenesis. ${ }^{49}$ In particular Azilsartan treatment decreased the hyperinsulinemia, improved the homeostasis model assessment (HOMA-IR) index and suppressed the overincrease in plasma glucose and insulin concentrations during oral glucose tolerance tests in obese Koletsky rats. In the same rat model, it reduced the basal plasma concentrations of glucose, triglyceride, and nonesterified fatty acids (NEFA). It has also been reported that azilsartan medoxomil improved insulin sensitivity in SHRs and reduced urinary protein excretion more potently than olmesartan medoxomil. ${ }^{37}$ Taken together, this evidence suggests the possible usefulness of azilsartan in the treatment of insulin resistance/metabolic syndrome, and its potential contribution to reduce the cardiovascular risk linked to glucose and lipid metabolism abnormalities in high risk individuals. Indeed, azilsartan medoxomil modulates other metabolic functions which can be involved in the atherosclerotic process. In cultured preadipocytes, 
azilsartan enhanced adipogenesis and induced the expression of adipokines, including leptin, adipsin, and adiponectin, and enhanced the expression of PPAR- $\alpha$ and $-\delta$, at a greater extent than valsartan. ${ }^{50}$

Hypertensive and/or diabetic patients often present microalbuminuria or overt proteinuria which are considered major risk factors for progression to end-stage renal disease and the development of cardiovascular disease. ${ }^{51}$ Reduction and normalization of proteinuria by drug treatment including the ARBs is associated with decreased risk for adverse renal outcomes, ${ }^{52}$ as previously discussed. Evidence from experimental studies suggest that similarly to other ARBs, azilsartan medoxomil may induce urinary albumin and protein excretion levels. This may possibly occur through the activation of several candidate mechanisms, including normalization of glomerular capillary pressure, inhibition of podocyte injury, inhibition of the proliferation of mesangial cells and inhibition epithelial-mesenchymal transition of tubular cell, although the exact mechanisms are unknown. ${ }^{36}$

Azilsartan medoxomil may modulate the cell growth, as it is indicated by the observation that it blocked the Ang II -induced activation of mitogen-activated protein kinases in vascular smooth muscle cells. Furthermore azilsartan medoxomil is a potent inhibitor of vascular cell proliferation even at low dosages. This effect is also evident in cells lacking $\mathrm{AT}_{1} \mathrm{R}^{50}$

Increased expression of plasminogen activator inhibitor type-I (PAI-1) in the vessel wall seems to accelerate atherosclerosis and it is involved in increasing the instability of atherosclerotic plaque. ${ }^{53}$ Azilsartan medoxomil reduced the expression of PAI-1 in the aortic wall of transgenic mice which overexpressed PAI-1 in VSMCs and were prone to atherosclerosis secondary to genetically determined ApoE deficiency. ${ }^{54}$ This was associated with a more stable atherosclerotic plaque. In the same mouse model azilsartan medoxomil reduced the PAI-1 levels also in the heart. Therefore it may contribute to reduce this profibrotic factor that is associated with the negative left-ventricular remodeling and the development of heart failure after myocardial infarction. ${ }^{55}$

These evidence suggest that azilsartan could exert pleiotropic cardioprotective effects beyond the expected beneficial effects of the potent and sustained blood pressurelowering action. Specific studies will be required to support this hypothesis.

\section{Conclusion}

Azilsartan medoxomil is a new compound proposed for the treatment of stage 1-2 hypertension, with its potent blood pressure-lowering ability associated with considerably better rates of hypertension control compared with other antihypertensive drugs including ARBs at standard doses. This may result in a better control of cardiovascular risk. In fact even a reduction of systolic blood pressure of $2 \mathrm{mmHg}$ to $3 \mathrm{mmHg}$ or more is associated with greater cardiovascular risk reduction as supported by in epidemiologic reports and interventional trials. ${ }^{56}$

The pharmacodynamic and pharmacokinetic properties suggest that azilsartan medoxomil should be used as an alternative agent for mild-to-moderate hypertension, particularly when other antihypertensive agents are not well tolerated or as an adjunctive drug in hypertensive patients not controlled with other antihypertensive agents. Evidence from experimental studies suggests that azilsartan medoxomil may have cardioprotective properties, through a number of other actions which are independent of effects on blood pressure. At present, there are no data available on the effects of azilsartan on cardiovascular morbidity and mortality as well as on key intermediate endpoints or disease markers.

\section{Disclosure}

MV has received honoraria, consultancies and advisory board with Novartis, Daiichi-Sankyo, Malesci, and BoehringerIngelheim. The authors have no other relevant affiliations or financial involvement with any organization or entity with a financial interest in or financial conflict with the subject matter or materials discussed in the manuscript apart from those disclosed.

\section{References}

1. Staessen JA, Wang JG, Thijs L. Cardiovascular protection and blood pressure reduction: a meta-analysis. Lancet. 2001;358:1305-1315.

2. Turnbull F; for the Blood Pressure Lowering Treatment Trialists' Collaboration. Effects of different blood-pressure-lowering regimens on major cardiovascular events: results of prospectively designed overviews of randomized trials. Lancet. 2003;362:1527-1535.

3. Egan BM, Zhao Y, Axon RN. US trends in prevalence, awareness, treatment, and control of hypertension, 1988-2008. JAMA. 2010;303(20): 2043-2050.

4. Chobanian AV, Bakris GL, Black HR, et al. The seventh report of the Joint National Committee on Prevention, Detection, Evaluation, and Treatment of High Blood Pressure. JAMA. 2003;289:2560-2572.

5. Paul M, Poyan Mehr A, Kreutz R. Physiology of local renin-angiotensin systems. Physiol Rev. 2006;86:747-803.

6. Atlas SA. The renin-angiotensin aldosterone system: Pathophysiological role and pharmacologic inhibition. J Manag Care Pharm. 2007; 13(Suppl B):9-20.

7. Min LJ, Mogi M, Iwanami J, et al. Cross-talk between aldosterone and angiotensin II in vascular smooth muscle cell senescence. Cardiovasc Res. 2007;76:506-516.

8. Elliott WJ, Plauschinat CA, Skrepnek GH, et al. Persistence, adherence, and risk of discontinuation associated with commonly prescribed antihypertensive drug mono-therapies. J Am Board Fam Med. 2007;20(1): $72-80$. 
9. Weir MR. Effects of renin-angiotensin system inhibition on end-organ protection: Can we do better? Clin Ther. 2007;29:1803-1824

10. The SOLVD Investigators. Effect of enalapril on mortality and the development of heart failure in asymptomatic patients with reduced left ventricular ejection fractions. $N$ Engl J Med. 1992;327(10): 685-691.

11. The SOLVD Investigators. Effect of enalapril on survival in patients with reduced left ventricular ejection fractions and congestive heart failure. N Engl J Med. 1991;325(5):293-302.

12. The CONSENSUS Trial Study Group. Effects of enalapril on mortality in severe congestive heart failure. Results of the Cooperative North Scandinavian Enalapril Survival Study (CONSENSUS). $N$ Engl J Med. 1987;316(23):1429-1435

13. Swedberg K, Held P, Kjekshus J, Rasmussen K, Rydén L, Wedel H. Effects of the early administration of enalapril on mortality in patients with acute myocardial infarction. Results of the Cooperative New Scandinavian Enalapril Survival Study II (CONSENSUS II). $N$ Engl J Med. 1992;327(10):678-684.

14. Biollaz J, Dürr J, Brunner HR, Porchet M, Gavras H. Escape from mineralocorticoid excess: the role of angiotensin II. J Clin Endocrinol Metab. 1982;54(6):1187-1193.

15. Boehm M, Nabel EG. Angiotensin-converting enzyme 2 - a new cardiac regulator. N Engl J Med. 2002;347(22):1795-1797.

16. Laight DW. Therapeutic inhibition of the renin angiotensin aldosterone system. Expert Opin Ther Pat. 2009;19(6):753-759.

17. Erbe DV, Gartrell K, Zhang YL, et al. Molecular activation of PPARgamma by angiotensin II type 1-receptor antagonists. Vascul Pharmacol. 2006;45(3):154-162.

18. Dahlof B, Devereux RB, Kjeldsen SE, et al. Cardiovascular morbidity and mortality in the Losartan Intervention For Endpoint reduction in hypertension study (LIFE): A randomised trial against atenolol. Lancet. 2002;359:995-1003.

19. Sawada T, Yamada H, Dahlof B, et al. Effects of valsartan on morbidity and mortality in uncontrolled hypertensive patients with high cardiovascular risks: KYOTO Heart Study. Eur Heart J. 2009;30: 2461-2469.

20. Tocci G, Paneni F, Palano F, et al. Angiotensin-converting enzyme inhibitors, angiotensin II receptor blockers and diabetes: a meta-analysis of placebo-controlled clinical trials. Am J Hypertens. 2011;24(5): 582-590.

21. Haller H, Ito S, Izzo JL Jr, et al. Olmesartan for the delay or prevention of microalbuminuria in type 2 diabetes. $N$ Engl J Med. 2011;364(10): 907-917.

22. Parving H-H, Lehnert $\mathrm{H}$, Brochner-Mortensen J, et al. The effect of irbesartan on the development of diabetic nephropathy in patients with type 2 diabetes. N Engl J Med. 2001;345:870-878.

23. Lewis E, Hunsicker LG, Clarke WR, et al. Renoprotective effect of the angiotensin-receptor antagonist irbesartan in patients with nephropathy due to type 2 diabetes. $N$ Engl J Med. 2001;345:851-860.

24. Owan TE, Hodge DO, Herges RM, et al. Trends in prevalence and outcome of heart failure with preserved ejection fraction. $N$ Engl J Med. 2006;355:251-259.

25. Pfeffer MA, McMurray JJ, Velazquez EJ, et al. Valsartan, captopril, or both in myocardial infarction complicated by heart failure, left ventricular dysfunction, or both. $N$ Engl J Med. 2003;349: 1893-1906.

26. Dickstein K, Kjekshus J, OPTIMAAL steering committee Effects of losartan and captopril on mortality and morbidity in high-risk patients after acute myocardial infarction: the OPTIMAAL randomised trial. Lancet. 2002;360:752-760.

27. Pitt B, Poole-Wilson P, Segal R, et al. Effect of losartan compared with captopril on mortality in patients with symptomatic heart failure: randomised trial - the Losartan Heart Failure Survival Study ELITE II. Lancet. 2000;355:1582-1587.

28. Yusuf S, Pfeffer MA, Swedberg K, et al. Effects of candesartan in patients with chronic heart failure and preserved left-ventricular ejection fraction: the CHARM-Preserved Trial. Lancet. 2003;362:777-781.
29. Yusuf S, Teo K, Anderson C, et al. Effects of the angiotensin-receptor blocker telmisartan on cardiovascular events in high-risk patients intolerant to angiotensin-converting enzyme inhibitors: a randomised controlled trial. Lancet. 2008;372:1174-1183.

30. Yusuf S, Teo KK, Pogue J, et al. Telmisartan, ramipril, or both in patients at high risk for vascular events. $N$ Engl J Med. 2008;358:1547-1559.

31. Yusuf S, Sleight P, Pogue J, et al. Effects of an angiotensinconverting-enzyme inhibitor, ramipril, on cardiovascular events in high-risk patients. The Heart Outcomes Prevention Evaluation Study Investigators. $N$ Engl J Med. 2000;342:145-153.

32. Schrader J, Luders S, Kulschewski A, et al. Morbidity and mortality after stroke, eprosartan compared with nitredipine for secondary prevention: Principal results of a prospective randomized controlled study (MOSES). Stroke. 2005;36:1218-1224.

33. Julius S, Kjeldsen SE, Weber M, et al. Outcomes in hypertensive patients at high cardiovascular risk treated with regimens based on valsartan or amlodipine: the VALUE randomised trial. Lancet. 2004;363:2022-2031.

34. Mori H, Ukai H, Yamamoto H, et al. Current status of antihypertensive prescription and associated blood pressure control in Japan. Hypertens Res. 2006;29:143-151.

35. Azilsartan Medoxomil (TAK 491) Investigator's Brochure. 3rd ed. Deerfield, IL: Takeda Global Research and Development Center, Inc; 2007.

36. Kusumoto K, Igata H, Ojima M, et al. Antihypertensive, insulinsensitising and renoprotective effects of a novel, potent and long-acting angiotensin II type 1 receptor blocker, azilsartan medoxomil, in rat and dog models. Eur J Pharmacol. 2011;669:84-93.

37. Smith DH, Cramer MJ, Neutel JM, et al. Comparison of telmisartan versus losartan: meta-analysis of titration-to-response studies. Blood Press Monit. 2003;8:111-117.

38. Dolan E, Stanton A, Thijs L, et al. Superiority of ambulatory over clinic blood pressure measurement in predicting mortality: the Dublin outcome study. Hypertension. 2005;46:156-161.

39. White WB, Weber MA, Sica D, et al. Effects of the angiotensin receptor blocker azilsartan medoxomil versus olmesartan and valsartan on ambulatory and clinic blood pressure in patients with stages 1 and 2 hypertension. Hypertension. 2011;57:413-420.

40. Sica D, White WB, Weber MA, et al. Comparison of the novel angiotensin ii receptor blocker azilsartan medoxomil vs valsartan by ambulatory blood pressure monitoring. J Clin Hypertens. 2011;13:467-472.

41. Mancia G, Facchetti R, Bombelli M, Grassi G, Sega R. Long-term risk of mortality associated with selective and combined elevation in office, home, and ambulatory blood pressure. Hypertension. 2006;47: $846-853$.

42. Kario K. Blood pressure variability in hypertension: a possible cardiovascular risk factor. Am J Hypertens. 2004;17:1075-1076.

43. Ojima $\mathrm{M}$, Igata $\mathrm{H}$, Tanaka $\mathrm{M}$, et al. In vitro antagonistic properties of a new angiotensin type 1 receptor blocker, azilsartan, in receptor binding and function studies. J Pharmacol Exp Ther. 2011;226(3):801-808.

44. Prasad A, Quyyumi AA. Renin-angiotensin system and angiotensin receptor blockers in the metabolic syndrome. Circulation. 2004;110: 1507-1512.

45. Negro R, Formoso G, Hassan H. The effects of irbesartan and telmisartan on metabolic parameters and blood pressure in obese, insulin resistant, hypertensive patients. J Endocrinol Invest. 2006;29:957-961.

46. Nishimura H, Sanaka T, Tanihata Y, Naito T, Higuchi C, Otsuka K. Losartan elevates the serum high-molecular weight-adiponectin isoform and concurrently improves insulin sensitivity in patients with impaired glucose metabolism. Hypertens Res. 2008;31:1611-1618.

47. Iimura O, Shimamoto K, Matsuda K, Masuda A, et al. Effects of angiotensin receptor antagonist and angiotensin converting enzyme inhibitor on insulin sensitivity in fructose-fed hypertensive rats and essential hypertensives. Am J Hypertens. 1995;8:353-357.

48. Iwai M, Chen R, Imura Y, Horiuchi M. TAK-536, a new AT1 receptor blocker, improves glucose intolerance and adipocyte differentiation. Am J Hypertens. 2007;20:579-586. 
49. Zhao M, Li Y, Wang J, et al. Azilsartan treatment improves insulin sensitivity in obese spontaneously hypertensive Koletsky rats. Diabetes Obes Metab. 2011;13(12):1123-1129.

50. Kajiya T, Ho C, Wang J, Vilardi R, Kurtz W. Molecular and cellular effects of azilsartan: a new generation angiotensin II recptor blocker. J Hypertens. 2011,29:2476-2483.

51. Agrawal V, Marinescu V, Agarwal M, McCullough PA. Cardiovascular implications of proteinuria: an indicator of chronic kidney disease. Nat Rev Cardiol. 2009;6:301-311.

52. Ruggenenti P, Schieppati A, Remuzzi G. Progression, remission, regression of chronic renal disease. Lancet. 2001;357:1601-1608.

53. Sobel BE, Taatjes DJ, Schneider DJ. Intramural plasminogen activator inhibitor type-1 and coronary atherosclerosis. Arterioscler Thromb Vasc Biol. 2003;23:1979-1989.
54. French CJ, Zaman AKMT, Sobel BE. The angiotensin receptor blocker, azilsartan medoxomil (TAK-491), suppresses vascular wall expression of plasminogen activator inhibitor type-i protein potentially facilitating the stabilization of atherosclerotic plaques. J Cardiovasc Pharmacol. 2011;58:143-148.

55. Sobel BE, Schneider DJ, Lee YH, et al. Insulin resistance increases PAI-1 in the heart. Biochem Biophys Res Commun. 2006;346: $102-107$.

56. Turnbull F, Neal B, Ninomiya T, et al. Effects of different regimens to lower blood pressure on major cardiovascular events in older and younger adults: meta-analysis of randomised trials. BMJ 2008;336(7653):1121-1123.

\section{Publish your work in this journal}

Integrated Blood Pressure Control is an international, peer-reviewed open-access journal focusing on the integrated approach to managing hypertension and risk reduction. Treating the patient and comorbidities together with diet and lifestyle modification and optimizing healthcare resources through a multidisciplinary team approach constitute key

\section{Dovepress}

features of the journal. This journal is indexed on American Chemical Society's Chemical Abstracts Service (CAS). The manuscript management system is completely online and includes a very quick and fair peerreview system, which is all easy to use. Visit http://www.dovepress.com/ testimonials.php to read real quotes from published authors.

Submit your manuscript here: http://www.dovepress.com/integrated-blood-pressure-control-journal 